\title{
Road kills of amphibians in different land use areas from Sharavathi river basin, central Western Ghats, India
}

\author{
Kadaba Shamanna Seshadri ${ }^{1}$, Amit Yadav ${ }^{2} \&$ Kotambylu Vasudeva Gururaja ${ }^{3}$ \\ ${ }^{1}$ Asoka Trust for Research in Ecology and the Environment, Royal Enclave, Sri Rampura, Jakkur P.O., Bengaluru, Karnataka 560064, India \\ ${ }^{2,3}$ Centre for Ecological Sciences, Indian Institute of Science, Bengaluru, Karnataka 560012, India \\ Email: ${ }^{1}$ seshadri@ atree.org; ${ }^{2}$ amit503sm @gmail.com; ${ }^{3}$ gururaj@ ces.iisc.ernet.in (corresponding author)
}

Date of publication (online): 26 November 2009 Date of publication (print): 26 November 2009 ISSN 0974-7907 (online) | 0974-7893 (print)

Editor: Ranjit Daniels

\section{Manuscript details:}

Ms \# 02148

Received 21 February 2009

Final received 25 August 2009

Finally accepted 09 November 2009

Citation: Seshadri, K.S., A. Yadav \& K.V. Gururaja (2009). Road kills of amphibians in different land use areas from Sharavathi river basin, central Western Ghats, India. Journal of Threatened Taxa 1(11): 549-552.

Copyright: @ Kadaba Shamanna Seshadri, Amit Yadav \& Kotambylu Vasudeva Gururaja 2009 Creative Commons Attribution 3.0 Unported License. JoTT allows unrestricted use of this article in any medium for non-profit purposes, reproduction and distribution by providing adequate credit to the authors and the source of publication.

\section{Author Details:}

K.S. SESHADRI is a researcher at ATREE, currently working on epiphytes and canopy ecology at Kalakad-Mundanthurai Tiger Reserve, Tamil Nadu. AMIT YADAV is a researcher at CES, currently working on ecological modeling in the watersheds of western Himalaya.

K.V. GuRURAJA is a researcher at CES, currently working on the effect of habitat fragmentation on diversity and distribution of amphibians in the Western Ghats.

Author Contribution: All authors have contributed equally in conceptualizing, data collection, analysis and writing of the paper.

Acknowledgements: We thank Srikant Naik for assisting in vehicular data collection, G. Supriya and $B$. Karthick for critical comments on the manuscript and Vijay Mohan Raj, Deputy Conservator of Forest, Sirsi Division for logistics.

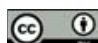

OPEN ACGESS | FREE DOWNLOAD
Abstract: A survey of amphibian mortality on roads was carried out in the Sharavathi river basin in the central Western Ghats. Road kills in three different land use areas: agricultural fields, water bodies and forests were recorded for four days along three $100 \mathrm{~m}$ stretches in each type of area. One-hundred-and-forty-four individuals belonging to two orders, eight families, 11 genera and 13 species were recorded in the survey. Kills $/ \mathrm{km}$ observed were: in forest 55 , agricultural fields 38 and water bodies 27, for an overall average of $40 \mathrm{kills} / \mathrm{km}$. Kill species compositions varied significantly between land use areas, but not overall kill rates.

Keywords: Amphibians, central Western Ghats, encounter rate, road kills, Sharavathi river basin, species composition.

\section{INTRODUCTION}

Amphibians are poor dispersers across different landscapes, on land or water (Marsh et al. 1999). Extinction-recolonization dynamics and dispersal ability also play a key role in structuring amphibian populations genetically (Berven \& Grudzien 1990; Sjogren 1991), and such poor dispersers are prone to local extinction and extirpation if their dispersal corridors/habitats are fragmented (Gururaja 2002). Roads are one of the barriers for dispersal of amphibians (Gibbs 1998). There are several studies outside India on the impact of roads and/or road kills on amphibians and their population density (Fahrig et al. 1995; Jackson 1996; Gibbs 1998; Carr \& Fahrig 2001; Hels \& Buchwald 2001; Dodd et al. 2004; Row et al. 2007; Santos et al. 2007) while in India there is a single study by Vijayakumar et al. (2001) from a protected area, Indira Gandhi National Park (southern Western Ghats).

In India the total length of roads and number of motorized vehicles have increased in the last 50 years (1951-2004) from 0.4 to 3.4 million kilometre and 0.3 to 30 million respectively (Rao \& Girish 2007). Such an enormous increase will certainly have detrimental influences on animals that crawl or move across roads. In this study we have attempted to quantify the road kills of amphibians across different land use areas along a $3.6 \mathrm{~km}$ stretch of national highway in the Sharavathi region of central of central Western Ghats with the following objectives: 1) to enumerate species composition and encounter rate of amphibians killed on the road due to vehicular movements, and 2) to assess the influence of different land uses on observed road kills.

\section{Study Area}

We selected a stretch of about $25 \mathrm{~km}$ from Talaguppa to Kathalekan (between $14.2^{\circ} \mathrm{N}$ $\& 74.9^{\circ} \mathrm{E}$ and $14.3^{\circ} \mathrm{N} \& 74.7^{\circ} \mathrm{E}$, altitude $\left.470-630 \mathrm{~m}\right)$ on $\mathrm{NH} 206$. This section of the road traverses through the terrains of central Western Ghats in Sharavathi river catchment. The major land use area types observed in the region are evergreen forest, semi-evergreen forest, moist-deciduous forest, agriculture, monoculture plantation, water bodies, cultivable land, waste land and built-up area (Sreekantha et al. 2007). We considered three land-uses namely, agriculture, water bodies and forest for the present study. Image 1 depicts the different segments of the road considered in the present study based on land-uses. The road segment in Talaguppa is predominated on either side with agriculture fields (paddy), near Manmane it is with water body, whereas near Kathalekan it is predominated with evergreen and semi-evergreen forest.

\section{Methods}

The road passing through three land-uses was sampled for killed amphibians on four consecutive days starting from 24 June 2008 till 27 June 2008. In each land-use, three $100 \mathrm{~m}$ segments were sampled with $100 \mathrm{~m}$ space in between. Total length of road 


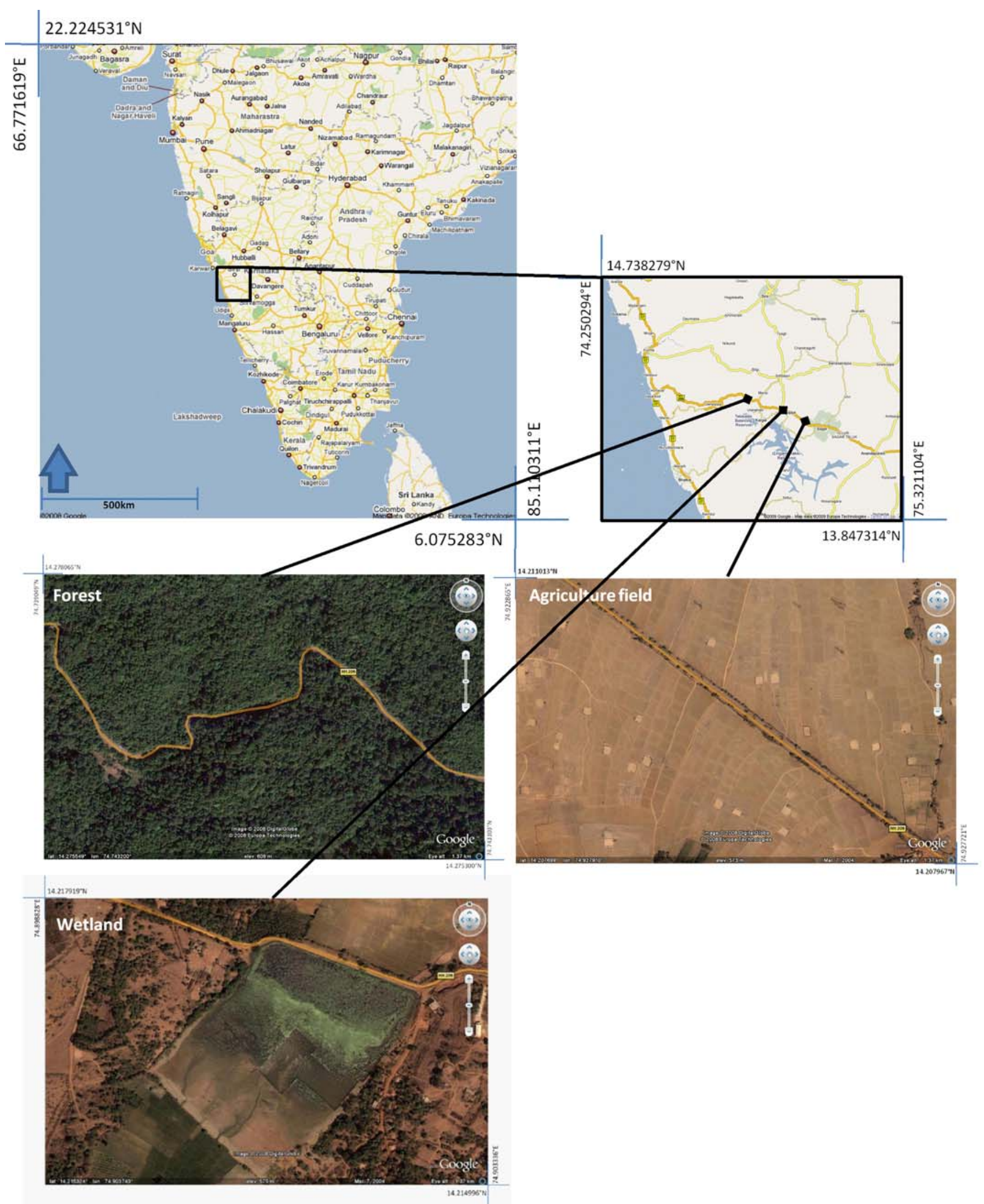

Image 1. Maps indicating the study area and zoomed in images of forest, agriculture field and wetland with sampling stretch of road (National Highway 206) passing through them (yellow line in the zoomed images). Image source: Google Earth, 2009. 
sampled was $3.6 \mathrm{~km}$ ( $3 \times 100 \mathrm{~m}$ in three land-uses for four days). Sampling was carried out between 0630-0830 hr, so as to record the accumulated road kills overnight (since majority of the amphibians are active during the night hours) and to minimize carcass loss due to scavenging by birds or other animals and by traffic during day hours. The roads were thoroughly searched for the presence of any killed amphibian. On sighting a road killed amphibian, it was identified up to species level (wherever possible) and the other organisms were also listed but not included in the analysis. Number of kills per kilometre is expressed as encounter rate. The remains were removed from the road to avoid redundancy. We have not collected or preserved any dead individuals/materials from this study.

The region receives maximum amount of rainfall (100$2000 \mathrm{~mm}$ ) for the year during June to September (Sreekantha et al. 2007). We preferred to carry out sampling during rainy season as rainfall seems to be the primary extrinsic factor controlling the timing of reproductive activity of amphibians (Duellman \& Trueb 1994).

The vehicular density on the road was monitored for two hours each in the early mornings (0630-0830 hr) and late evenings on three days (1830-2030 hr). Overall vehicular density was $29.69 / \mathrm{hr}$, considering all three days. On further dividing, heavy motor vehicle was $12.54 / \mathrm{hr}$, followed by light motor vehicle $9.15 / \mathrm{hr}$ and two wheeler $8 / \mathrm{hr}$. The study area has a major tourist spot, the world famous Jog Falls, which is located within $10 \mathrm{~km}$ from all our sampling sites, attracts large number of tourists during weekends and more precisely during monsoon period. Hence a detailed study on vehicular movement during weekends and holidays are essential for better understanding of traffic in the region. Due to various constraints, intensive vehicular monitoring was not possible and the counts in this study are just representative of the trends. One way Analysis of Variance (ANOVA) was tested on species composition and encounter rates in three land-uses $(\mathrm{k}=3, \mathrm{n}=12)$ to know the variation in them.

\section{RESULtS}

Amphibians belonging to two orders, eight families, 11 genera and 13 species were recorded in the survey. Table 1 shows conservation status and encounter rate of road killed amphibians (individuals $/ 1.2 \mathrm{~km}$ ). A total of 144 individuals over $3.6 \mathrm{~km}$ were recorded during the study, of which $32 \%$ was in agriculture section, $22 \%$ was in water body section and $46 \%$ in the forest section. Seven amphibian species were recorded from the forest section, followed by six in the paddy section and three from the water body section.

The road kill encounter rate was highest in forest with 55 kills/ $\mathrm{km}$, followed by the agriculture with $38.33 \mathrm{kills} / \mathrm{km}$ and water body being the least with $26.66 \mathrm{kills} / \mathrm{km}$. Species composition between land-uses were significantly different $(\mathrm{F}=5.44, \mathrm{P}=0.04)$, however, overall kill between land-uses $(\mathrm{F}=1.36, \mathrm{P}=0.3)$ as well as different days $(\mathrm{F}=0.23 ; \mathrm{P}=0.87)$ did not show statistically significant difference. This shows that, irrespective of the different land-uses, the numbers of road kills were similar, though the species composition differed.

Among amphibians, Duttaphrynus melanostictus had maximum kills $(\mathrm{n}=17)$ in the forest section followed by Ichthyophis beddomei a limbless amphibian $(\mathrm{n}=5)$ and stream dwelling Nyctibatrachus sp. $(\mathrm{n}=3)$. In agriculture, Fejervarya sp. $(\mathrm{n}=22)$ had maximum
Table 1. Amphibian road kills and encounter rate (individual/1.2km) across land-uses

\begin{tabular}{|c|c|c|c|c|c|c|}
\hline & Species & Status * & $\begin{array}{l}\text { Agri- } \\
\text { culture }\end{array}$ & $\begin{array}{l}\text { Water } \\
\text { body }\end{array}$ & Forest & Total \\
\hline & Bufonidae & & & & & \\
\hline 1 & $\begin{array}{l}\text { Duttaphrynus melanostictus } \\
\text { Dicroglossidae }\end{array}$ & LC & & & 17 & 17 \\
\hline 2 & Euphlyctis cyanophlyctis & LC & 2 & 1 & & 3 \\
\hline 3 & Fejervarya cf. rufescens & LC & & & 1 & 1 \\
\hline 4 & Fejervarya sp. & & 20 & 2 & & 22 \\
\hline 5 & $\begin{array}{l}\text { Hoplobatrachus tigerinus } \\
\text { Microhylidae }\end{array}$ & LC & & & 1 & 1 \\
\hline 6 & Microhyla ornata & LC & & 9 & & 9 \\
\hline 7 & $\begin{array}{l}\text { Ramanella cf. montana } \\
\text { Nyctibatrachidae }\end{array}$ & NT & 1 & & & 1 \\
\hline 8 & $\begin{array}{l}\text { Nyctibatrachus sp. } \\
\text { Ranidae }\end{array}$ & & & & 3 & 3 \\
\hline 9 & $\begin{array}{l}\text { Hylarana malabarica } \\
\text { Ranixalidae }\end{array}$ & LC & 1 & & & 1 \\
\hline 10 & $\begin{array}{l}\text { Indirana sp. } \\
\text { Rhacophoridae }\end{array}$ & & & & 2 & 2 \\
\hline 11 & $\begin{array}{l}\text { Polypedates cf. occidentalis } \\
\text { Icthyophiidae }\end{array}$ & $s$ DD & 1 & & & 1 \\
\hline 12 & Ichthyophis sp. & & 1 & & 3 & 4 \\
\hline 13 & Ichthyophis beddomei & LC & & & 5 & 5 \\
\hline 14 & Unidentified frogs & & 20 & 20 & 34 & 74 \\
\hline & Total & & 46 & 32 & 66 & 144 \\
\hline
\end{tabular}

Note: * As per Global amphibian assessment (www.globalamphibians.org as accessed on $18^{\text {th }}$ of October 2008).

LC - Least Concern; DD - Data Deficient; NT - Near Threatened.

kills, while it was Microhyla ornata $(n=9)$ in water body. No species had similar road kill encounter rates in all land-uses.

In case of Fejervarya sp. and unidentified frogs $(\mathrm{n}=74)$, there is a possibility of more than one species being present, as majority of them provided mere clues like limbs, hands, mandibles to recognize as frogs due to maceration by repeated movement of vehicles.

We compared our study with Vijayakumar et al. (2001), which was carried out for about $171 \mathrm{~km}$ in the Indira Gandhi National Park. Although our sampling length was $3.6 \mathrm{~km}$, which is just about $2 \%$ of $171 \mathrm{~km}$, nonetheless comparison was made as it was the only other available study on amphibian road kills in India. Our study showed higher road kill encounters of amphibians of $40 / \mathrm{km}$ compared to $2 / \mathrm{km}$. On comparing the species composition, Vijayakumar et al. (2001) enlisted five families and three species with 311 kills, whereas our study enlisted 13 species belonging to eight families with 144 kills. In their study, Duttaphrynus melanostictus had highest road kills (145) followed by members of Ranidae family, while Fejervarya sp. and Duttaphrynus melanostictus had 22 and 17 road kills respectively from our study.

The other organisms observed as road kills belonged to the following groups viz; invertebrates (crab, butterfly, insect, earthworm, centipede and snail), reptiles (Malabar Pit Viper (Trimeresurus malabaricus), Bamboo Pit Viper (T. gramenius), unidentified keelback (Xenochrophis sp.) and unidentified calotes (Calotes sp.) and mammals (rat).

\section{Discussion}

According to the study there is a high incidence of road killed amphibians and marked differences in the species composition of road kills among different land use areas of forest, agriculture and water bodies. The difference in the 
species composition in land-uses is indicative of habitat specificity of species. Fejervarya sp. are semi-aquatic, open canopy dwellers, generally prefer agriculture fields and stagnant water bodies, hence their road kill encounters were maximum at agriculture fields. Similarly, encounter rate of Ichthyophis beddomei and Nyctibatrachus sp. in forest stretches, indicates the affinity of these species to torrential streams and stream beds in forest. Interestingly, absence of significant variation among total road kills per land-use emphasises that irrespective of species composition, almost equal number of individuals are killed in each land-use on each day.

There is a $90 \%$ increase in the road kill encounter rate in this study compared to Vijayakumar et al. (2001). There are several factors influencing such disparity between the studies. Vehicular traffic is the major driving factor influencing the road kills. This was not mentioned in Vijakumar et al.'s (2001) paper. Apart from that, difference in sampling effort $(171 \mathrm{~km}$ vs $3.6 \mathrm{~km}$ ), vegetation composition, amphibian species composition, geography and protection status of the study area (National Park vs non-protected area) must have influenced these two studies.

Since the habitats inhabited by frogs outside the protected areas (PA) are very large (Das et al. 2006), such studies outside the PAs have to be done in order to document the impact of road kills on amphibians and its contribution to local, regional and global level amphibian decline. The study would have given a clear picture about the relationship of road kills and vehicular density, if the vehicular density was monitored more extensively covering the whole week as we observed that the vehicle density increased drastically during the weekends. Nevertheless, this study gives an impetus for further studies in the Western Ghats where large habitats favourable to amphibians are cut across by extensive road networks and which may influence the local extinction and decline in amphibian population.

\section{References}

Berven, K.A. \& T.A. Grudzien (1990). Dispersal in the Wood Frog (Rana sylvatica): Implications for genetic population structure. Evolution 44(8): 2047-2056.

Carr, L.W. \& L. Fahrig (2001). Impact of road traffic on two amphibian species of differing vagility. Conservation Biology 15(2001): 10711078.
Das, A., J. Krishnaswamy, K.S. Bawa, M.C. Kiran, V. Srinivas, N.S. Kumar \& K.U. Karanth (2006). Prioritisation of conservation areas in the Western Ghats, India. Biological Conservation 133(2006): 1631.

Dodd, C.K. Jr., W.J. Barichivich \& L.L. Smith (2004). Effectiveness of a barrier wall and culverts in reducing wildlife mortality on a heavily traveled highway in Florida. Biological Conservation 118(2004): 619631.

Duellman, W.E. \& L. Trueb (1994). Biology of Amphibians. The Johns Hopkins University Press Maryland. xxi+670pp.

Fahrig, L., J.H. Pedlar, S.E. Pope, P.D. Taylor \& J.F. Wegner (1995). Effect of road traffic on amphibian density. Biological Conservation 73(1995): 177-182.

Gibbs, J.P. (1998). Amphibian movements in response to forest edges, roads, and streambeds in southern New England. Journal of Wildlife Management 62(2): 584-589.

Global Amphibian Assessment (2008). <www.globalamphibians.org>. as accessed on $18^{\text {th }}$ of October 2008.

Gururaja, K.V. (2002). Effect of habitat fragmentation on distribution and ecology of anurans in some parts of central Western Ghats. PhD. Thesis, Kuvempu University.

Hels, T. \& E. Buchwald (2001). The effect of road kills on amphibian populations. Biological Conservation 99(2001): 331-340.

Jackson, S.D. (1996). Underpass systems for amphibians. In: Evink, G.L., P. Garrett, D. Zeigler \& J. Berry (eds.). Trends in Addressing Transportation Related Wildlife Mortality, Proceedings of the transportation related wildlife mortality seminar. State of Florida Department of Transportation, Tallahassee, FL. FL-ER-58-96.

Rao, R.S.P. \& M.K.S. Girish (2007). Road kills: Assessing insect casualties using flagship taxon. Current Science 92(6):831-837.

Row, J.R., G. Blouin-Demers \& P.J. Weatherhead (2007). Demographic effects of road mortality in black ratsnakes (Elaphe obsoleta). Biological Conservation 137(1): 117-124.

Santos, X., G.A. Llorente, A. Montori, M.A. Carretero, M. Franch, N. Garriga \& A. Richter-Boix (2007). Evaluating factors affecting amphibian mortality on roads: the case of the common toad Bufo bufo, near a breeding place. Animal Biodiversity and Conservation 30(1): $97-104$.

Sjogren, P. (1991). Extinction and isolation gradients in metapopulations: The case of the pool frog (Rana lessonae). Biological Journal of the Linnean Society 42(1-2): 135-147.

Sreekantha, M.D., S. Chandran, K.M. Divakar, G.R. Rao, K.V. Gururaja \& T.V. Ramachandra (2007). Fish diversity in relation to landscape and vegetation in central Western Ghats, India. Current Science 92(11): 1592-1603.

Vijayakumar, S.P., K. Vasudevan \& N.M. Ishwar (2001). Herpetofaunal mortality on roads in the Anamalai Hills, southern Western Ghats Hamadryad 26(2): 253-260. 